\title{
Research on the relationship between network embeddedness and the innovation performance of enterprise --Based on the moderating effect of network capacity
}

\author{
Min Wei ${ }^{a}$, Lu Ma ${ }^{b}$ \\ School of Management, Guangxi University of Science and Technology, Liuzhou, 545006, China \\ aweimin7201@163.com, bmalu6655@163.com
}

\begin{abstract}
Based on the theory of the network embeddedness and network capacity, the paper puts the network embeddedness, network capacity and innovation performance into a unified theoretical framework and builds the theoretical model of the relationship between them. At the same time the thesis puts forward the theoretical assumptions on the basis of previous research. This paper argues that relational network embeddedness and structural network embeddedness respectively have a significant positive correlation with the enterprise innovation performance, and the network capacity in the relationship between network embeddedness and enterprise innovation performance has a positive regulation, and proposes the dimension of network capability that including network vision capability, network construction capacity, relationship management capability and relationship combination ability have a positive regulation in the relationship between the network embeddedness and innovation performance for the first time.
\end{abstract}

Keywords: network embedding; innovation performance; network capacity; network vision ability; network construction ability.

\section{Introduction}

The twenty-first Century is the era of network economy. If the enterprises want to overcome the enormous pressure of competition caused by economic globalization it must maintain its competitiveness through innovation. The innovation has become the only way to keep the vitality and continuous operation of the enterprise. However, it is very difficult for single enterprise to improve the knowledge, information, capital and other key resources for innovation. The achievement of innovation performance needs a number of enterprises to work together, because most enterprises cannot complete all aspects of innovation. This requires enterprises to break through their own boundaries, through different forms of network embeddedness, enable the enterprise to have the strategic choice of a broader and more business opportunities for innovation. The network embeddedness has become one of the path selection of enterprise innovation and the network embeddedness theory has become an important tool in the research of enterprise innovation. For any one enterprise in the dynamic and complex network environment, the key to win is to properly integrate and absorb the information and resources of external network partners.

\section{Theoretical Basis and Research Hypothesis}

\subsection{Relational Network Embeddedness and Enterprise Innovation Performance}

The relational network embeddedness refers to the participants set up the interpersonal relationship in the process of interaction with the society. It describes the relationship characteristics about understanding, commitment, trust and reciprocity. It mainly involves in the personality aspect of social network and emphasizes the strength and quality of relationship between network partners (Coleman, Kats \& Mezel, 1996), the enterprise accesses to the innovative resources through the sharing of resources between enterprises directly [1].

Granovetter (1985) define the strength of relationship through interaction frequency, intimacy, emotional intensity and the level of reciprocal exchange and divides it into strong ties and weak ties [2]. As the representative of some scholars Granovetter and Burt claim that weak ties has the key role 
to innovation performance of enterprise. They think that the weak relation intensity have access to delivery heterogeneous resources and avoid duplication and redundancy of resources due to the strong ties, as a result of the break up effect of innovation, promote enterprise innovation. Talmud \& Mescn (1997) think that the influence of strong ties and weak ties on enterprise performance is also affected by the market conditions, when market conditions in a uncertain state, strong ties will improve enterprise innovation performance, and when the market environment is stabilized that the weak ties is more favorable to improve innovation performance [3].Although weak relationship has advantage of dissemination of information crossing organization, also can bring more information for the enterprise and has special value in the information search and sharing. But this paper argues that in the complex and volatile market environment, in addition to Chinese is also attached great importance to the "relationship", strong relationship to promote the enterprise innovation performance is more favorable [4]. The relationship quality refers to the degree of behavior uniformity and tacit understanding between the target enterprise and other network subject. This is also a prerequisite for further cooperation between the two sides. Dyer and Singh [5] think that good partnership between enterprises is the prerequisite for further cooperation relations between the two sides and the enterprise timely access to the authenticity and reliability resources and information. So it can better promote enterprise innovation. At the same time, based on the view of resource, Hunt and Morgan (1999) proposed that the relationship has a good relationship of loyalty and trust are more persistent. It is conducive to the continuous innovation of enterprises [6]. Thus, this paper puts forward the following assumption:

H1: The relational network embeddedness and the innovation performance of enterprise has a positive correlation.

\subsection{Network Structure Embedded and Enterprise Innovation Performance}

Structural network embeddedness emphasizes the structural characteristics of network members embedded in the network and concerned about the impact of its location on the network to its economic behavior and performance. The scholars usually use the enterprise network density, scale and the center of position to measure.

The network location usually use the network centrality to express. It refers to the core business occupies a significant position through complex network links in the overall structure of the overall network and this position has certain recognition and active connection. Enterprises occupy the network center and has a wealth of structural holes, the more able to control more resources. It is more likely to influence other members in the network (Chung, Singh and Lee, 2000) [7], the influence of network is greater. Therefore, it is more able to set high prices for their products and services to improve performance (Baum, 2000). At the same time, it also can strengthen the respect and trust to the enterprises in the network center (Gulati, 1999) [8]; so the enterprise is located in the center of cooperation to establish a cooperative relationship with other organizations is relatively easy. It will help enterprises to carry out technical cooperation and knowledge exchange at different levels, and improve the performance of enterprise innovation. Because it is located in the center of the companies, it will be quicker to receive new information and grasp the change of market demand to improve the enterprise innovation performance.

The network scale refers to the number of other network subjects which are directly related to the enterprise (Burt, 1983; Marsden, 1990). According to the theory of enterprise network, the scale of the network connection determines the received level of information and resources. Different types of connection for the enterprise bring different resources. The larger the network scale and the more diverse network members, the more heterogeneous and complementary resources, and then improve the internal resources of enterprises to support enterprise innovation better[9].Grant raised a view from the perspective of competition that enterprises must expand the scale of network contact with other enterprises to improve their competitive advantage. Vanhaverbeke confirmed that the larger the network scale, the more able to improve the enterprise's innovation performance [10].

The network density reflects the attribute of overall architecture of the embedded network enterprises. It is used to measure the connection of the nodes in the network and reflects the cohesion 
of the network and the degree of aggregation. Hansen et al (2001) pointed out that when the direct link between the network cooperative entities accounts for the higher proportion of the total number of possible links, it would increase the trust between enterprises and the efficient flow of information communication will become more efficient. It is more likely to form a common mode of behavior. Phelps C (2010) believes that the organization trust, sharing common rules and patterns of behavior between the high density members of the network will promote the transfer of tacit knowledge and enterprise innovation performance will be more and more high [11]. High density network will form more contact between enterprises and make the enterprise access to heterogeneous resources and knowledge. It is conducive to the occurrence of innovative activities [12]; dense network as an approximation of the "closed" system is beneficial to the common standards of enterprises, and more likely to develop a relationship of mutual trust and common behavior pattern to promote the relationship between enterprises in capital investment. Therefore, this paper puts forward the following assumption:

H2: Network structure embedded and enterprise innovation performance has a positive correlation.

\subsection{Regulatory Role of Network Capacity}

The era of network economy makes communication links between enterprises more frequent and the communication barrier is broken gradually. At the same time, the business activities are embedded into a variety of networks passive or active. Network embeddedness provides a convenient way for enterprises to obtain external innovation resources, knowledge and information, but enterprises want to integrate, convert, absorb, use these high quality and complementary resources, itself needs to have a strong network capacity. The difference of network capability is the important reason for the difference of innovation performance [13].

First of all, the network vision capability is considered to be an overall strategic network capability. It can identify potential partners who provide complementary resources for the enterprise, and be keen to discover new opportunities for innovation in network relationships [14]. The better the network vision, the stronger the perception ability of the enterprise to the external potential opportunities, the higher the sensitivity. The sufficient network embeddedness can get more contact network for the enterprise and the enterprise also has the ability to identify and select high quality partners to promote the enterprise innovation performance; secondly, the ability of network construction includes the experience, resources, knowledge acquisition and absorption during the cooperation of the enterprise. In the case of extensive network embedded, the stronger the ability of network construction, the enterprise can obtain a large amount of resources, information and knowledge to transform, absorb and use to make it become effective innovative resources. The relationship management and the relation combination capability as the ability of optimization, coordination the binary and multi network cooperative relations. It evaluates network partners through the exchange of individual level, organizational level and strategic level to determine the specific allocation of network resources (time and other scarce resources). So it can obtain more reliable supply of resources, so as to reduce the risk and cost of innovation, enhance the enterprise innovation success probability [15] (Figure 1).

H4: The network capability positively regulates the relationship between network embeddedness and innovation performance.

H4a: The network vision capability positively regulates the relationship between network embeddedness and innovation performance.

H4b: The network construction capability positively regulates the relationship between network embeddedness and innovation performance.

H4c: The relationship management capability positively regulates the relationship between network embeddedness and innovation performance.

H4d: The relation combination capability positively regulates the relationship between network embeddedness and innovation performance. 


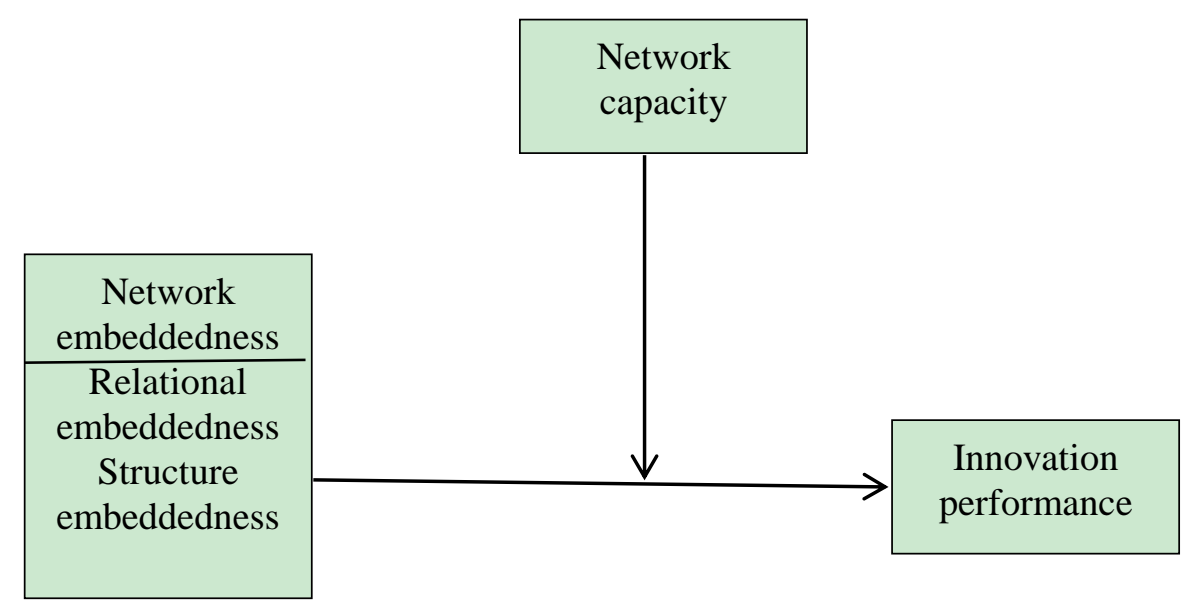

Fig. 1 The Theoretical Model of this paper

\section{Management implications}

In the era of complex and changeable network economy, enterprises must actively embedded in the network environment, and give full play to their own initiative to construct the network structure of strategic. In order to control the flow of resources and effective information and get rich with more opportunities enterprises need to occupy the core network position in the enterprise network relations. And should strengthen ties with partners, and actively expand its network scale, to ensure access to more heterogeneous resources.

The enterprise should improve their own network capacity as the key of construction. Based on the previous research, the network capacity is divided into four dimensions. In order to improve the innovation performance of enterprises, it needs to actively cultivate the ability of the enterprise network vision, network construction capacity, relationship management ability and the relation combination ability. First, the enterprise leaders should make strategic thinking and planning from the perspective of network, and strengthen their ability to identify and judge the opportunity, timely capture the hidden opportunities in the external network; Secondly, the leader should actively develop and adapt to the dynamic network and is conducive to the promotion of enterprise organization structure learning, the establishment and maintenance of various technical means of network relations, optimize and adjust to the persistent network partner cooperation relationship; In addition, Business leaders need to strengthen ties with external organizations (e.g., government agencies, chambers of Commerce and industry associations, etc.), in order to look for potential partners with high quality.

\section{Conclusion}

First of all, in the study of the influence of network embedding on innovation performance, this paper only assume the role of network capacity, this research is also affected by other mediator and moderator of the unknown, the future needs more overall research; Secondly, due to different industries and different scale, the enterprise network capacity and the innovation requirements are not the same, it may lead to subsequent samples do not accurately reflect the problem. The future study should as far as possible to select the similar enterprises as samples; finally, in this paper, we do not take into account the impact of network dynamics on enterprise innovation performance, and future research needs to consider the characteristics of network dynamics.

\section{Acknowledgments}

This research was financially supported by the Master of innovation project 2016, NO201611. 


\section{References}

[1] Coleman J S, Coleman J S. Foundations of social theory [M]. Harvard University Press, 199.

[2] Granovetter M. Economic action and social structure: the problem of embeddedness [J]. American Journal of Sociology, 1985, 91 (3): 481-510.

[3] Lavie D. Alliance Portfolios and Firm Performance: A Study of Value Creation and Appropriation in the U. S. Software Industry [J]. Strategy Management Journal, 2007, 28 (3): 1187-1212.

[4] Cai Binqing, Chen Guohong. Chain industry cluster network relationship, organizational learning and innovation performance research [J]. Research and development, 2013, 04:126-133.

[5] Zhao Liangjie, song Bo. Technical interdependence, organizational dual capability and alliance innovation performance: the perspective of dynamic network [J]. Research and development management, 2015, 01:113-123.

[6] Dyer J, Singh H. The relational view; Cooperative strategy and sources of inter-organizational competitive advantage [J].Academy of Management Review, 1998, 23(4); 660-679.

[7] Devi R, Gnyawal, Ravindranath Madhavan. Cooperative networks and competitive dynamics: A structural embeddedness perspective [J]. Academy of Management Review, 2001, 26(3): 431.

[8] Dong Baobao. Research on the relationship between network structure and competitive advantage-Based on the perspective of dynamic capability mediated effect [J]. Journal of management, 2012, 01:50-56.

[9] Cheng Cong, Xie Hongming. Study on social network embedding and relationship performance of cluster enterprises: Based on the perspective of relationship tension [J]. Nankai business review, 2012, 04:28-35.

[10] Grant R M. Toward a Knowledge- based Theory of the Firm [J].Strategic Management Journal, 1996, 17(Winter Special Issue): 109-122.

[11]Dou Hongbin, Wang Zhengbin. The influence of network structure, knowledge resources acquisition on the growth performance of enterprises: a case study of Xi'an electronic industry cluster [J]. Research and development management, 2012, 01:44-51.

[12] Vanhaverbeke W, Gilsing V, Beerkens B V, et al.The Role of Alliance Network Redundancy in the Creation of Core and Non- core Technologies [J].Journal of Management Studies, 2009, 46.

[13]Phelps C C. A Longitudinal Study of The Influence of Alliance Network Structure and Composition on firm Exploratory Innovation [J]. Academy of Management Journal, 2010,53 (4): 890- 913.(1): 217- 219.

[14] Valente TW. Network models of the diffusion of innovations. Cresskill, NJ: Hampton Press, 1995.

[15]Burt RS. The network structure of social capital. Paper presented at the conference on social networks and social capital, Duke University, Durham, NC, 1998. 